\title{
Pengelolaan Koperasi Canggu Beach Transport Sebagai Wadah Pengusaha Angkutan Umum Pariwisata di Echo Beach Canggu Badung
}

Ni Made Sumiatia, 1, I Putu Anoma, 2

113sumiati@gmail.com,2putuanom@unud.ac.id

a Program Studi S1 Destinasi Pariwisata, Fakultas Pariwisata,Universitas Udayana, Jl. Dr. R. Goris, Denpasar, Bali 80232 Indonesia

\section{Abstract}

The growth of tourism industry is a push to growth of community's creativity in developing their potential, by utilizing the opportunities created from the presence of tourism, such as tourism public transport services that is created by Koperasi Canggu Beach Transport. This study aims to know the management applied as well as the strenght and weakness of implementation. The research method that used to identify the management of tourism public transport service in Canggu is qualitative data and quantitative data obtained using the techniques of observation, interview and literature study. Purposive sampling is used to determine the informants. The result of this study concluded that the management of Koperasi Canggu Beach Transport has been appropriate according to planning and organizing which done before. Monthly meetings are held in an effort to control and evaluate the result of the project that already done. There are some suggestions to create new queue system that applied and also needed an increasement of socialization through social media to introduce and also as a promotion media.

Keywords: Tourism, Management,Tourism Transport Mode,Transportation

\section{PENDAHULUAN}

Kegiatan pariwisata secara umum merupakan salah satu industri andalan dalam meningkatkan pendapatan masyarakat serta sebagai penghasil devisa negara, aktifitas pariwisata secara langsung melibatkan masyarakat lokal, masyarakat dapat mengekspresikan dirinya dengan adanya dorongan yang kuat dari kegiatan pariwisata untuk berkreasi dan lebih kreatif dalam mecari dan menciptakan peluang dari adanya perkembangan pariwisata yang semakin pesat, seperti halnya bekerja pada sebuah hotel dengan kemampuan atau skill yang dimiliki, disamping itu juga masyarakat dapat mengasah kreatifitasnya dengan membuka sebuah usaha, baik usaha kerajinan serta mengelola jasa angkutan umum pariwisata.

Angkutan umum pariwisata merupakan salah satu unsur penting dalam kegiatan pariwisata, merupakan sebuah sarana yang dibutuhkan wisatawan untuk menuju destinasi wisata. Dalam setiap kegiatan transportasi terdapat lima unsur yang tidak dapat dipisahkan, kelima unsur tersebut adalah kendaraan, awak kendaraan, jaringan jalan, tujuan wisata dan wisatawannya. Kelima unsur tersebutlah yang menciptakan adanya sebuah perjalannan wisata. Echo Beach adalah salah satu destinasi wisata yang berlokasi di Desa Canggu, Kecamatan Kuta Utara Kabupaten Badung. Destinasi wisata Echo Beach ini menyuguhkan keindahan pesisir pantai yang tak kalah indahnya dengan pantai lain yang ada di Bali, wisatawan yang datang berkunjung awalnya adalah wisatwan pecinta atraksi surfing namun, seiring dengan dikenalnya destinasi wisata Echo Beach banyak wisatawan yang berdatangan untuk menikmati pemandangan pesisir yang indah dan menyaksikan sunset disore hari. Seiring dengan adanya perkembangan pariwisata dikawasan Echo Beach masyarakat setempat tidak melewatkan peluang yang ada, kesempatan tersebut direspon baik dengan menciptakan sebuah usaha seperti pedagang souvenir, penyewaan papan surfing dan penyediaan jasa angkutan umum pariwisata. Kecerdasan masyarakat dalam menangkap peluang yang tercipta untuk menyediakan jasa angkutan umum pariwisata dengan membentuk sebuah organisasi yang di namakan Koperasi Canggu Beach Transport, merupakan alternatif baru untuk memberdayakan masyarakat lokal di Desa Canggu. 
Seiring dengan adanya perkembangan pariwisata dikawasan Echo Beach masyarakat setempat tidak melewatkan peluang yang ada, kesempatan tersebut direspon baik dengan menciptakan sebuah usaha seperti pedagang souvenir, penyewaan papan surfing dan penyediaan jasa angkutan umum pariwisata. Kecerdasan masyarakat dalam menangkap peluang yang tercipta untuk menyediakan jasa angkutan umum pariwisata dengan membentuk sebuah organisasi yang di namakan Koperasi Canggu Beach Transport, merupakan alternatif baru untuk memberdayakan masyarakat lokal di Desa Canggu. Dalam pelaksanaan kegiatan jasa angkutan pariwisata tentu terdapat beberapa hambatan serta gesekan yang terjadi antar anggota yang tergabung didalamnya serta miss komunikasi dengan pihak penyelenggara jasa angkutan pariwisata lainnya, perlu adanya penataan untuk memperbaiki pengelolaan selanjutnya.

Berdasarkan hal tersebut maka diperlukan adanya penelitian terkait Pengelolaan Koperasi Canggu Beach Transport Sebagai Wadah Pengusaha Angkutan Umum Pariwisata Di Echo Beach Canggu Badung, untuk mengetahui jenis pengelolaan yang diterapkan serta strength and weakness dari pelaksanaan yang sudah berlangsung.

\section{TINJAUAN PUSTAKA}

Terdapat beberapa konsep yang digunakan untuk menganalisis data yang didapat di lapangan, yaitu :

1. Konsep pariwisata menurut Undang - Undang No. 10 Tahun 2009 Pasal 1 butir 3 dimana yang dimaksud dengan pariwisata adalah berbagai macam kegiatan wisata dan didukung berbagai fasilitas serta layanan yang disediakan oleh masyarakat, pengusaha, pemerintah dan pemerintah daerah.

2. Konsep Transportasi adalah kegiatan pemindahan barang (muatan) dan penumpang dari suatu tempat ke tempat lain. Dalam transportasi ada dua unsur terpenting yaitu pemindahan/pergerakan (movement) dan secara fisik mengubah tempat dari barang (comoditi) dan penumpang ke tempat lain, Salim (2000).

3. Konsep Angkutan Umum dan Moda Transportasi Darat yang terdiri dari angkutan orang dan barang, Standar Pelayanan Angkutan Orang dan Pelayanan angkutan orang dengan Kendaraan Bermotor Umum tidak dalam trayek, (UU Republik Indonesia Nomor 22 Tahun 2009 Tentang Lalu Lintas Dan Angkutan Jalan)

4. Konsep Pengelolaan menurut Terry (2005) yang terdiri dari perencanaan (planning), pengorganisasian (organizing), penggerakan (actuating) dan Pengawasan (controlling).

\section{METODE PENELITIAN}

Echo Beach terletak di Desa Canggu, Kecamatan Kuta utara, Kabupaten Badung. Adapun ruang lingkup yang digunakan yakni Pengelolaan Koperasi Canggu Beach Transport di Echo Beach. Jenis dan sumber data yang digunakan yakni menggunakan data kualitatif (Kusmayadi dan Sugiarto, 2000), data yang diperoleh berupa informasi atau keterangan mengenai gambaran umum lokasi penelitian, moda angkutan dan pengelolaan Koperasi Canggu Beach Transport di Echo Beach. Jenis data kuantitatif (Kusmayadi, 2000), adapun data diperoleh berupa jumlah kendaraan, tabel kunjungan, rute, harga dan jumlah anggota Koperasi Canggu Beach Transport. terdapat dua sumber data dalam penelitian ini yakni data primer dan data skunder (Arikunto,2010).

Dalam mengumpulkan data terdapat tiga teknik, yakni : observasi yang artinya peneliti melakukan sebuah pengamatan dengan jenis observasi nonpartisipan, Kusuma (1987). Wawancara dilakukan melalui komunikasi secara langsung tentang suatu objek yang diteliti dan telah dirancang sebelumnya (Muri Yusuf, 2014), untuk mendapatkan jawaban terkait pengelolaan Koperasi Canggu Beach Transport Sebagai Wadah Pengusaha Angkutan Umum Di Echo Beach Cangggu, serta dokumentasi peristiwa atau kejadian sejarah kehidupan (life histories), biografi, karya tulis, dan cerita (Muri Yusuf,2014), berupa struktur anggota, laporan pengelolaan dan foto-foto yang berkaitan tentang kegiatan Koperasi Canggu Beach Transport.

Penentuan informan dalam proses penelitian menggunakan teknik purposive yaitu dipilih dengan pertimbangan dan tujuan tertentu (Sugiyono, 2015). Teknik analisis data dalam penelitian ini menggunakan teknik analisis deskriptif kualitatif yaitu metode dalam penelitian status kelompok manusia, suatu 
objek, suatu kondisi, suatu sistem pemikiran ataupun suatu kelas peristiwa pada masa sekarang, Sugiyono (2009).

\section{HASIL DAN PEMBAHASAN}

Koperasi Canggu Beach Transport merupakan salah satu badan usaha yang mewadahi pengusaha angkutan umum pariwisata yang diselengarakan oleh masyarakat lokal di Echo Beach, Banjar Canggu, Desa Canggu Kecamatan Kuta Utara Kabupaten Badung. Organisasi Koperasi Canggu Beach Transport ini awalnya dibentuk pada tahun 2007 oleh sekelompok masyarakat di desa Cannggu.

Inisiatif tersebut muncul diawali dengan adanya perkembangan kawasan Echo Beach yang mulai ramai dikunjungi wisatawan, sehingga salah satu warga masyarakat yakni I Nyoman Mudita melirik potensi usaha yang dapat dijalankan untuk menunjang kegiatan pariwisata di kawasan Echo Beach. Potensi usaha tersebut yakni dibidang jasa transportasi wisata, pada akhirnya I Nyoman Mudita merangkul masyarakat yang sebelumnya memang sudah menjadi guide freeland dikawasan Kuta dan Seminyak.

Sehingga, peluang usaha yang terdapat dikawasan Echo Beach dapat digarap dan buah manis dari perkembangan pariwisata dapat dirasakan secara langsung oleh masyarakat setempat, maka dari itu terbentuklah sebuah organisasi Koperasi Canggu Beach Transport, sebagai wadah aspirasi masyarakat, di samping itu guna menghindari adanya ketimpangan dalam pengelolaannya. Organisasi tersebut sudah berbentuk badan hukum yang dinaungi oleh Koperasi Canggu Beach Transport.

\section{A. Pengelolaan Koperasi Canggu Beach Transport di Echo Beach}

Pengelolaan yang dilakukan oleh pihak Koperasi Canggu Beach Transport sesuai pada fungsi pengelolaan yang dikemukakan oleh Terry (2005) menjelaskan bahwa manajemen adalah suatu proses yang membedakan atas perencanaan, pengorganisasian, penggerakan pelaksanaan dan pengawasan, dengan memanfaatkan baik itu ilmu atupun seni, agar dapat menyelesaikan tujuan yang telah ditetapkan sebelumnya. Berdasarkan fungsi maka pengelolaan Koperasi Canggu Beach Transport dijabarkan sebagai berikut :

1. Perencanaan Koperasi Canggu Beach Transport Terdapat beberapa indikator yang menjadi sumber acuan dalam perencanaan pengeloaan Koperasi Canggu Beach Transport yaitu sebagai berikut :

a. Melakukan pendataan terhadap masyarakat yang hendak bergabung untuk mempermudah proses pelaksanaan

b. Pengadaan musyawarah untuk mewadahi aspirasi anggota yang bertujuan mengindari adanya gesekan yang terjadi antar anggota, serta menetapkan ketentuan yang berlaku dalam penyelengaraannya

c. Melakukan sosialisasi dengan pihak pengelola jasa angkutan umum serupa seperti, Taxi, Blue Bird dan sebagainya, bahwa dikawasan Canggu terdapat aturan bahwa pengelola transportasi lainnya hanya dapat menggunakan sistem dropship.

d. Pemasangan pamflet terkait larangan masuknya Taxi, Bluebird dan sebagainya di kawasan Canggu.

e. Pembentukan koperasi sebagai wadah hukum untuk menaungi Koperasi Canggu Beach Transport.

f. Pelaksanaan bakti sosial yang diselenggarakan setiap tahunnya.

Sejauh ini ini perencanaan yang terselenggara sudah berjalan cukup baik meskipun sempat terjadi gesekan dalam pelaksanaanya namun permasalahan tersebut dapat diselesaikan.

\section{Pengorganisasian Koperasi Canggu Beach Transport}

Koperasi Canggu Beach Transport pertama kalinya dibentuk beranggotakan 16 orang, anggota yang tergabung memang sudah memiliki pengalaman sebelumnya sebagai tour guide freeland. Seiring dengan semakin berkembangnya tingkat kunjungan wisatwan ke Echo Beach terdapat peningkatan jumlah anggota yang tergabung, disamping itu organisasi Koperasi Canggu Beach Transport juga berupaya untuk memberdayakan masyarakat yang ada di Banjar Canggu dan sekitarnya saat ini anggoota yang terdaftar sejumlah 36 orang dengan masing-masing anggota menggunakan satu mobil kepemilikan secara pribadi, bahkan beberapa anggota 
memiliki driver namun ada beberapa agggota yang aktif dan pasif.

Berikut adalah struktur organisasi Koperasi Canggu Beach Transport dapat dilihat pada bagan:

Struktur organisasi Koperasi Canggu Beach Transport

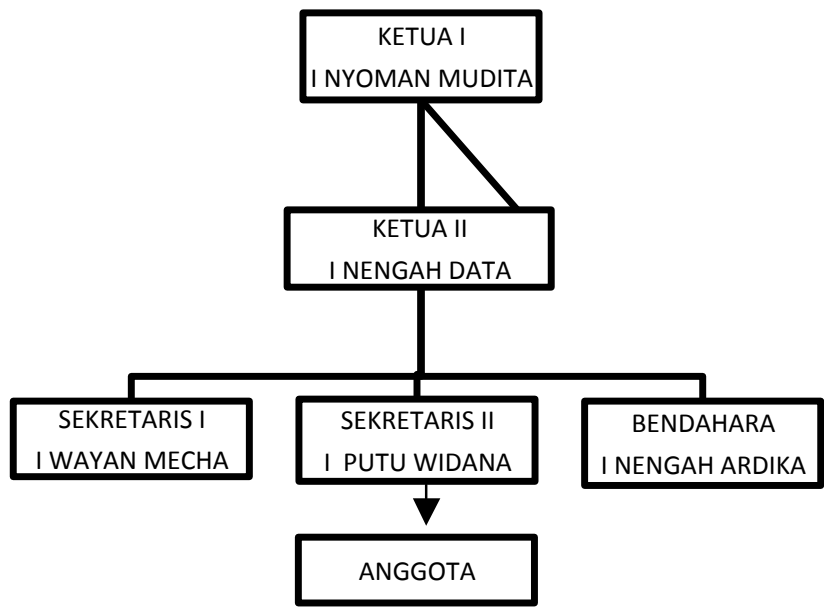

Sumber : Dokumentasi Penelitian, 2016

a. Ketua, bertugas untuk memantau dan menilai sistem kerja yang sudah terlaksana

b. Sekretaris, bertugas sebagai adminstrasi yang mengurus segala jenis keperluan yang berkaitan dengan surat menyurat terkait pengelolaan Koperasi Canggu Beach Transport.

c. Bendahara bertugas untuk mengelola dan memantau arus keuangan seperti khas masuk dan pengeluaran khas dalam pengelolaan Koperasi Canggu Beach Trasport

d. Anggota melakukan sistem antrean dan secara bergilir menghantarkan wisatawan yang menggunakan jasa angkutan Koperasi Canggu Beach Transport

3. Pelaksanaan Pengelolaan Koperasi Canggu Beach Transport

Upaya pelaksanaan yang dilakukan dalam pengelolaan Koperasi Canggu Beach Transport adalah implementasi dari perencanaan yang telah disusun sebelu

mnya yakni pelaksanaan kerja, penetapan jumlah anggota Koperasi Canggu Beach Transport serta sistem kerja yang diterapkan. Koperasi Canggu Beach Transport beroprasi selama 24 jam dengan menggunakan sistem antrean yang tidak berpedoman atau siapa yang tercepat mencari antrean mendapat paling awal.
Wisatawan melakukan pemesanan secara langsung, di samping itu pihak anggota Koperasi Canggu Beach Transport juga melakukan kerja sama dengan akomodasi seperti villa, hotel dan restoran yang terdapat dikawasan Canggu. Pihak hotel merekomendasikan wisatawan yang menginap untuk menggunakan jasa transportasi tersebut, sedangkan pihak organisasi berkewajiban untuk memberikan fee sebesar $10 \%$ dari hasil yang didapat. Namun, apabila wisatawan memesan secara langsung fee tersebut digunakan sebagai khas anggota. Pihak angota juga berkewajiban untuk mendonasikan pendapatannya sebagai khas anggota, besaran donasi sesuai kriteria pendapatan berikut ;

a. Rp.100.000 - Rp. 300.000 maka anggota berkewajiban menyumbangkan pendapatannya sebesar Rp. 5.000

b. Rp. 301.000 - Rp.500.000 berhak menyumbangkan pendapatannya sebesar Rp. 10.000

c. Rp. 501.000 dan sterunya maka berhak menyumbangkan pendapatan sebesar $\mathrm{Rp}$ 20.000

4. Pengawasan Pengelolaan Koperasi Canggu Beach Transport

Pengawasan serta memonitoring dilakukan oleh pihak ketua guna memantau semua proses kegiatan yang sedang berlangsung dengan melakukan evaluasi hasil kerja secara keseluruhan, melakukan musyawarah atau rapat bulanan. Musyawarah dilakukan guna untuk mengevaluasi khas masuk dan khas keluar yang ada selama proses kegiatan berlangsung untuk menghindari adanya kejanggalan dalam pengelolaan tersebut, selain itu juga untuk meninjau hasil kerja yang sudah dilaksanakan. Menyaring masukan masingmasing anggota untuk meningkatkan kinerja dari Koperasi Canggu Beach Transport, untuk mengetahuai kekuatan dan kekurangan dari pelayanan yang disediakan yang akan digunakan sebagai acuan untuk meningkatkan kualitas pelayanan.

\section{SIMPULAN DAN SARAN}

\section{SIMPULAN}

Koperasi Canggu Beach Transport terselenggara mengingat adanya perkembangan pariwisata dikawasan Canggu, 
pengelolaan Koperasi Canggu Beach Transport mengacu pada fungsi pengelolaan yang dikemukakan oleh Terry (2005), diantaranya terdapat perencanaan, pengorganisasian, pelaksanaan dan pengawasan yang sudah berlangsung, sejauh ini pengelolaan yang terselenggara sudah berjalan dengan baik adanya beberapa kerjasama dan menjalin komunikasi dengan baik dengan pihak penyedia transportasi online yang betujuan untuk menghindari gesekan yang tidak diingikan ditandai dengan memasang pamflet larangan disetiap sudut dikawasan Canggu.

\section{SARAN}

Dalam operasional Koperasi Canggu Beach Transport sistem antrian yang dilakukan oleh anggota sebaiknya perlu dipertimbangkan guna dalam pemerataan pendapatan dari masing-masing anggota dengan membuat sistem antrian yang dikelompokan berdasarkan hari dan pembagian jumlah anggota selanjutnya jadwal oprasionalnya disesuaikan dengan kesepakatan. Selain itu pihak Koperasi Canggu Beach Transport sebaiknya melakukan sosialisasi melalui media sosial selain sebagai media promosi juga media pengenalan bahwa dikawasan Canggu terdapat organisasi yang mengelola angkutan pariwisata untuk mengindari terjadinya gesekan dengan pengelola jasa angkutan lainnya.

\section{DAFTAR PUSTAKA}

Anonim 2009. Undang - Undang No. 10 Tahun 2009 Pasal 1 butir 3. Tentang kepariwisataan.

Anonim 2009. Undang-Undang Republik Indonesia Nomor 22 Tahun 2009. Tentang Lalu Lintas Dan Angkutan Jalan

Arikunto, S. 2010. Prosedur Penelitian : Suatu Pendekatan Praktik (Edisi Revisi). Rineka Cipta. Jakarta.

Basuki, Imam., Setiadi, Amos. 2015. Potensi Angkutan Umum Pariwisata di Daerah Istimewa Yogyakarta. Yogyakarta: Jurnal

Budiartha, Nyoman. 2011. Peranan Transportasi Dalam Pariwisata ( Pemilihan Daerah Tujuan Wisata (Dtw/Destinasi) Oleh Wisatawan). Denpasar. Jurnal

Goerge R. Terry (2005), Principle Of Managrment, Alexander Hamilton Institute, New York

Kusmayadi., dan Sugiarto. E. 2000. Metodologi Penelitian Dalam Bidang Kepariwisataan. Gramedia Pustaka Utama.Jakarta

Kusuma, S.T. 1987. Psiko Diagnostik

Muri yusuf,2014. Metode Penelitian Kuantitatif, Kualitatif \& Penelitian Gabungan. Jakarta: Prenada Media Group
Salim, H. A. Abbas, 2000. Menejemen Transportasi. Jakarta: PT Raja Grafindo Persaja

Sugiyono. 2009. Metode Penelitian Bisnis (Pendekatan Kuantitatif, Kualitatif, dan R\&D). Alfabeta. Bandung. 